\title{
Living Organ Donation, Beneficient Helping, \& the Kantian Concept of Partial Self-Murder
}

\author{
Archimedes C. Articulo \\ College of Arts and Sciences, Cagayan State University, Tuguegarao City, Philippines \\ Email: chitocsu@gmail.com \\ Received 7 September 2014; revised 29 September 2014; accepted 12 October 2014 \\ Copyright ( 2014 by author and Scientific Research Publishing Inc. \\ This work is licensed under the Creative Commons Attribution International License (CC BY). \\ http://creativecommons.org/licenses/by/4.0/ \\ (c) (1) Open Access
}

\section{Abstract}

This paper deals with the ethical issues concerning living organ donor transplantation in the context of Immanuel Kant's Ethical Theory. It primarily aims to refute the common perception about Kant's categorical opposition to organ transplantation as violative to his concept of duty of selfpreservation (transplantation as a form of mutilation or partial suicide). In this paper we will argue that: 1) Kantian concept of mutilation, or partial self-murder, should be perceived within the context of Kant's prohibition of killing oneself; 2) Kant does not prohibit all forms of organ donation as contrary to duty of self-preservation (i.e., duty to maintain quality of life and donation as violative to the strict prohibition against mutilation). Organ donation could hardly be considered as mutilation or contrary to duty of self-preservation if the following conditions are satisfied: 1) the organ to be donated and the surgical procedure involved, would not pose grave risk (e.g. physical disability and death) to the donor; and 2) the moral personality of the donor would not be at risk by donating his organ.

\section{Keywords}

Categorical Imperatives, Ethics, Bioethics, Medical Ethics, Organ Donation, Organ Transplantation

\section{The Categorical Duty of Self-Preservation}

Discussing man's duty of self-preservation, Kant in the Groundworks made this statement:

"I cannot dispose of man in my own person by mutilating, damaging or killing him." (G429)1.

The passage seems to suggest that violating the strict duty of self-preservation can be committed not only

${ }^{1}$ Ellington's translation of Kant’s Groundworks, hereafter cited as $(\mathrm{G})$ with page numbers; Kant, Emmanuel. Groundworks for Metaphysics of Morals. Translated and edited by James Ellington, (1981), Cambridge: Hackett Pub. Co., Inc. 3rd edition. 
by killing oneself but also by “mutilating” or “damaging” one’s body.

Using the aforementioned passage as their sole basis, some (or most) Kantian bioethicists and critics argue that the problem of living organ donor transplantation in general is not only based on the duty not to kill oneself, but also with the strict duty "not to deprive oneself of integral organs". They say that depriving oneself of an organ is mutilation-and since the practice of organ donation necessarily involves the dismemberment of bodily organs, then it is clear that living organ donation is mutilation. If organ donation is mutilation then all forms of organ donation cannot be accepted in Kantian ethics.

With this interpretation in mind, critics of Kant proceeded in passionately dismissing him and his theory as obsolete and fundamentalist. Kantian ethics, they claim, is something that we should abandon in the face of great advancements in modern medicine and surgery.

It is submitted, however, that if we read again the subject passage in the Groundworks, we can clearly see that the same does not provide an adequate description of what constitutes mutilation of the body. This should provide any careful reader of Kant to at least suspect any criticism based solely on such passage to be unfounded.

One surely needs to go beyond the Groundworks to know whether or not organ donation is, in deed, for Kant, a form of mutilation.

\section{The Concept of Self-Preservation and Mutilation in the Metaphysics of Morals}

In his Metaphysics of Morals (on Doctrine of Virtue), Kant provides a more elaborate account on how the duty of self-preservation could be violated and what he meant by mutilation:

"The first, though not the principal, duty of a human being to himself as an animal being is to preserve himself in his animal nature. The contrary of this is willful physical death or killing oneself, which can be thought as either to total, suicide, or only partial, mutilating oneself. Mutilating oneself can in turn be either material, depriving oneself of certain integral, organic parts, that is maiming oneself, or formal, depriving oneself (permanently or temporarily) of one's capacity for the natural (and so indirectly for the moral) use of one's powers." (DV 6: 421)

Self-preservation is violated when one kills or mutilates oneself and mutilation is committed when we deprive ourselves with integral organic parts or when we deprive ourselves with our capacity for the natural use of our natural powers.

The interpretation that all forms of organ donation are prohibited in Kantian ethics has two obvious assumptions: one, Kant categorically prohibits all forms of amputation of organs (mutilation is simply the deprivation or "cutting off' of organic parts) and the other, self-preservation is simply the preservation of the organic parts of the human body.

While it is true that our duty to preserve ourselves in our animal nature does require us categorically not to commit suicide, it does not, however, categorically requires us to keep or to preserve all our bodily organs intact at all times, at all cost. For Kant the prohibition against mutilation (viz., when understood simply as amputation of organic parts) accepts an exemption.

One exemption, which Kant himself provided in the Metaphysics of Morals, is the "mutilation" or amputation of a dead organ to save the life of a person having it. Kant writes,

"[But] to have a dead or diseased organ amputated when it endangers one's life...cannot be counted as a crime against one's own person.” (DV 6:422)

The passage clearly suggests that to "mutilate" or "amputate" an organ, if keeping it would kill an individual, is justifiable. The overriding reason for mutilation in this case is not because the organ to be amputated is dead (or diseased) but because mutilation, or the amputation of organ, is necessary for self-preservation.

So when do we count "mutilation" or "amputation of organic parts" as a crime against one's own person? The answer is quite clear: when mutilation or amputation of an organ is performed to harm or injure oneself or when one intends a "willful partial physical death".

When self-preservation or the preservation of life is intended, mutilation ceases to be a crime against one's

${ }^{2}$ Mary Gregor's translation of Kant's Doctrine of Virtue hereafter cited as (DV) with page numbers; Kant, Immanuel. Metaphysics of Morals Translated and Edited by May Gregor, (1996), Cambridge University Press. 
own person. It is important therefore to think of mutilation in the context of the Kantian prohibition against willful killing of oneself-Kant, after all clearly claimed that willful physical death "can be thought of as either total, suicide, or only partial, mutilating oneself”. If so, then self-preservation should also be construed in terms of the preservation of the human life and not necessarily with the unconditional preservation of the human body. Because, again, if we maintain the belief that self-preservation means the strict duty of maintaining/preserving the body on its animal nature, then Kant would have barred even the amputation of diseased organs.

By no means that I am arguing here that the human body is not to be valued-indeed, for Kant, we should. I am just pointing out that there are cases where Kant allows the "cutting off" or the amputation of an integral part (or parts) of the human body without committing a crime against one's own person. Mutilation, in this context, does not simply refer to amputation of organic parts-amputation of organs does not in itself constitute a crime. What makes it a crime is when it is purposefully performed not to preserve life but to destroy it.

Kant condemns "amputation of organs" as "mutilation" when it is simply intended to debilitate, or to deprive oneself of strength, of spirit and of vigor-it is the act committed by someone against himself out of contempt or hatred of life, a person who debases himself by treating his body as a mere means to his trivial ends. Such willing of partial physical death makes amputation of organs a contemptuous act of mutilation. This, not the amputation of organ itself, makes it wrong.

At this point, it is interesting to note that if Kant allows the removal of diseased organs to preserve life, it is hard to think why Kant would have prohibited the "insertion" of healthy organs to one's body to save it. It is important to consider that Kant wrote long before organ transplantation is possible-and this fact should be counted not to justify his "perceived" obsoleteness, but in clarifying his concept of mutilation as a "destruction" of the body and life.

Another salient aspect of Kantian concept of mutilation is the formal form of mutilation i.e. the deprivation of oneself (permanently or temporarily) of one's capacity for the natural (and so indirectly for the moral) use of one's powers.

For Kant, these natural powers include powers of spirit, whose exercise is possible only through reason; powers of soul, they include memory, imagination, etc.; and powers of the body, cultivated through gymnastics (DV 6:445). Mutilating or destroying the basic stuff (the matter) in a human being, that is, his body, is to destroy man's natural capacity (hence, the possibility) to rationally determine and freely pursue his own ends.

As rational agents we set for ourselves our own projects or ends in life (as simple as taking one's family to the park every weekends), we decide what sort of life we would like to lead (for instance, living a learned profession, or a life of trade and commerce, etc.) and we aspire for the moral perfection as our moral end. However, these ends would be impossible to realize without maintaining (i.e. preserving) our human body and cultivating its powers-because only through our body (and through our other natural powers) we could possibly act on our ends (DV 6:445). Amputation of healthy limbs, self-inflicted blindness, and other acts therefore is condemnable because it destroys the integrity of a human being as end-setting agents.

Hence, Mutilation, in this regard, is condemned because it assaults man's rationality and freedom (i.e. as a being who reflects and sets his own ends) - that is, it undermines the "personality" of a human being and his quality of life. However, this also implies that once an amputation of organ is shown that it does not impinge or assaults the personal integrity of a person, or undermines his quality of life, amputation of organ for a noble cause, in light of this consideration, is permissible.

The last consideration that should be discussed concerning Kantian notion of mutilation is the issue of selling bodily parts or the destruction of these bodily parts as mere means to arbitrary ends-specifically, for better livelihood. According to Kant,

"To deprive oneself of an integral part or an organ (to maim oneself)-for example to give away or sell a tooth to be transplanted into another's mouth, or to have oneself castrated in order to get an easier livelihood as a singer, and so forth-are ways of partially murdering oneself." (DV 6:423)

Here, it is important to note that removing (and transplanting) even of the non-vital parts of the human body (as simple as tooth!) is considered to be "partially murdering oneself". Was it because the $18^{\text {th }}$ century Kant thinks that extracting a tooth would debilitate a person, hence, a form of mutilation?

The reason why Kant claimed that the removal of tooth is partial-murder is clearly provided by Kant himself in his example: the removal of teeth (for transplantation in another's mouth) is wrong because of the underlying 
intention why it was removed-to sell it. The tooth was treated as an item for sale. This, in effect, turns the human body as a mere means that is arbitrarily treated-a mere source of saleable tooth! ${ }^{3}$

The same is true with the case of castration (or the surgical removal of the testes in males) ${ }^{4}$. Kant would have not minded it if castration is performed for self-preservation (for instance to inhibit hormone secretion in cases of prostate cancer in men). But the intention why the testes are "castrated" in Kant's example is morally questionable: for one to have a better livelihood, for example, as a singer. Just like in the case of selling tooth, the body, in castrating the testes, is treated as a mere means, that is, as a mere means of livelihood.

The fact that Kant made no special distinction between the removal of simple "bits and pieces" of the human body (e.g. removal of tooth) and the integral parts of the body (e.g. castration of the testicles) confirms that what makes their willful deprivation in man wrong - lies not on their removal per se or on what is being removed (a tooth or a testes) but on the reason why they are to be removed: as a commodity of exchange and as a means of livelihood.

Here, we could see that for Kant, simple parts of the human body (e.g. a tooth) which is non-vital to bodily survival possess a value equal to any other parts of the body (e.g. organs like a heart or a kidney) -the reason is unmistakable, for they are all parts of the human body which should not be treated as mere means. To dispose any of them as a mere commodity or to use them as mere means of livelihood is considered debasing the priceless worth of human beings.

To provide one more example to drive this point, Kant has this to say about the wrongful disposal of another of those human bits and pieces: the human hair-

"To have something cut off that is part, but not an organ of the body, for example, one hair, cannot be counted as a crime against one's own person-although cutting one's hair in order to sell it is not altogether free from blame" (DV 6:423)

Tooth and hair (include even eye lashes and pubic hairs), once they are removed or cut off from the body for the purpose of selling them is, for Kant, debasing the dignity of human beings and contrary to duty of self-preservation.

After exhausting this only part of the Metaphysics of Morals (and the only written work of Kant) which directly deals with mutilation, we are now prepared to present a better picture of Kantian concept of mutilation as a vice or a transgression of one's duty to self-preservation. In summary, we have thus:

1) Amputation of organs constitutes a crime against one's own person when it is performed primarily to harm, injure or kill oneself. But when self-preservation or the preservation of life is intended, amputation of organs ceases to be a violation against duty to oneself.

2) Amputation of organs constitutes a crime against one's own person when it undermines an individual's personal integrity or personality-that is, as a being who has the capacity to determine and pursue his various ends (in contemporary terms, when it undermines an individual's quality of life).

3) Amputation of organs constitutes a crime against one's own person when the primary reason is the sale of organs or when "amputation" of organs is considered as means of livelihood.

We can consider these as the Kantian conditions which we can use in determining whether or not organ donation of living donors is mutilation or as violative to Kant's concept of duty of self-preservation.

We now apply living organ donation, as we know it today, in light of the three conditions mentioned above, and see whether or not there is a basis in the claim that Kant categorically prohibits all forms of organ donation.

\section{Living Organ Donation as Beneficent Helping}

A person who commits mutilation aims at the destruction of the body and life-the infliction of unnecessary pain and injury to the body - this is not the aim of the donor in organ donation.

\footnotetext{
${ }^{3}$ Here, it should be corrected that Kant does not condemn "tooth transplantation" as mutilation simply because of the "extraction" and "transplantation" of tooth-it is the selling of tooth, not the extraction or the transplantation, that is condemned. Kantian critics like Dr. Land who thinks that Kant is against every form of organ transplantation, based on this "tooth transplantation" example, has clearly missed the point. See Land, W. (1999). Ethics in Living Donor Organ Transplantation. Transplantation Center of the University of Munich. Langenkefks Archives of Surgery. Oct., 1999.

${ }^{4}$ Castration also happens in females which involves the removal of ovaries. But we have good reasons to believe that Kant, in the passage, was referring to male castration. For several centuries (until prohibited by Pope Leo XIII in the late $19^{\text {th }}$ century) castration of the genitalia was practiced to produce male sopranos or contraltos called castrati (castrados) for ecclesiastical chants in the Roman Catholic Church.
} 
The living donor wills not his partial death but the preservation of life. The objection that what is "amputated" in organ donation is a healthy, not diseased, organ is missing the point: to amputate a healthy organ just to destroy it is one thing, to amputate a healthy organ to save life is another. As long as what is willed is life preservation, and not partial death, as long as what is aimed at is "my neighbor's good", not "my own harm"-then there is no reason, in light of the first condition, to condemn certain forms of organ donation (kidney and bone marrow donation, for instance) as akin to Kantian mutilation.

The objection that organ donation is a means not for self-preservation but the preservation of other self is not adequate to dismiss organ donation as un-Kantian. The fact that the donor wills the saving of other's life, without himself abandoning his life, not only renders organ donation as permissible, it could even give moral content to his action.

Kant values the preservation of the human life-this is the reason why he strongly condemns suicide and this is also the very reason why he allowed "mutilation" or "damaging" of the body if it would further the life of an individual (i.e. amputation of diseased organ). If the donor makes a sacrifice to express the same valuation of life, it is not difficult to conceive how Kant has positively reacted with "modern day" transplant donors.

There is a deep symmetry between preserving one's life and preserving the life of another. And there is no great divide that exists between amputation of deceased organs to save one's life and the amputation of healthy organs to save another's life.

Our duty of self-preservation also tells something about our duty to help others in preserving themselves-the only condition we have is not to help when the cost of helping is the abandonment or grave disruption of our own lives and basic projects. This inevitably brings us at the heart of Kant's concept of beneficence as mutual aid:

"To be beneficent, that is, to promote according to one's means the happiness of others in need, without hoping for something in return, is everyone's duty. For everyone who finds himself in need wishes to be helped by others...the maxim of common interest, of beneficence toward those in need, is a universal duty of human beings just because they are to be considered fellowmen, that is, rational beings with needs, united by nature in one dwelling place so that they can help one another" (DV 6:453)

In the casuistical questions, Kant provides a limitation to our duty of help:

"How far should one expend one's resources in practicing beneficence? Surely not to the extent that he himself would finally come to need the beneficence of others." (DV 6:454)

The limitation of helping others is clear: we are not to help if the cost of helping will make us need the help of others ourselves. In the case of organ donation the limitation is clear: don't get yourself killed or gravely harmed, wherein you yourself will need help, when you are to help others preserve themselves. Keeping this limitation in mind, we are bound by duty to actively participate in the life of others-making their ends as our ends, to further them as we can ( $\mathrm{G} 430)$.

But what are the ends of others which we should also make as our ends? Are we to make every single end of other individuals our ends? Kant clarifies:

"It is impossible to assign determinate limits to the extent of this sacrifice. How far it should extend, depends, in large part, on what each persons' true needs are in view of his sensibilities, and it must be left to each to decide for himself." (DV 6:393)

There are ends that an agent could easily give up on discovering that he could not realize them without aid, for instance going to a movie on a day we are short of cash, and ends that an agent cannot rationally abandon, for instance preserving oneself from sickness, injury or death. The latter is what we call true ends ${ }^{5}$. In view of our duty of beneficence, this type of ends determines the condition where we are duty bound to help others.

What is involved in organ donation is meeting the true needs of others. The life of the organ recipient is at risk, and if help were not given (e.g. a kidney), the recipient would die. If the nature of the need to be met determines whether it is an occasion where helping is needed of us, then donating an organ, in this case, is one of those occasions, given our desire, ability and our position to help, where we could extend help to others in grave need.

In living kidney donation (and other non-lethal organ donations), the organ donor can help, if he chooses to, without crossing the limit of beneficence. In other words, the organ donor in kidney donation (and other non-

\footnotetext{
${ }^{5}$ Herman offers a good account on the difference between true needs and other forms of needs. See Herman, B. (2001). The Practice of Mor-
} al Judgment. USA: Harvard University Press. pp. 69-70. 
lethal organ donations) can help save life without necessarily giving up his own life, sacrificing his projects and other needs because of the advancement of high technology surgery today (unlike in the time of Kant when the removal of kidney means certain death) ${ }^{6}$. What is involved in organ donation is not to help "till it hurts" (hence, not the same with ordinary act of helping)—because organ donation in deed hurts—but the donor, if he thinks he can and if he chooses to, can help not "till it hurts", but rather, "till it kills" (hence, a greater form of sacrifice than ordinary helping).

The second condition tells us that amputation of organs constitutes a crime against one's own person when it undermines the personality of an individual or degrades his quality of life. It is a common belief that that organ donation leads to the shortening of life and to the deterioration of the donor's quality of life.

This belief constitutes one of the many facets of the so-called "Kantian objection" against all forms of organ donation as contrary to one's duty of self-preservation (that is, self-preservation in terms of preservation of the "personality" and "quality of life" of donors).

This common "Kantian" argument against organ donation goes this way: As free and rational agents, we define both our basic (or true) ends (e.g. exercising our rational agency, to preserve one's life, to live life with our loved ones, etc.) and our other ends in life (e.g. to go on camping, hiking, watching a movie, etc.). Our ability to pursue these ends or projects and enjoy them characterizes the quality of life that one must be allowed to have. Since organ donations (including kidney and bone marrow donations) undermines the donor's ability to pursue his freely defined ends (i.e. to play hard sports that the donor loves to do) and shortens his life (hence imposing an uncalled limitation to the enjoyment of his ends), then all forms of organ donation are unacceptable because it violates the donor's duty of self-preservation.

Now, we should take note that the objection is based on some alleged empirical facts: "that it shortens life" and "it deteriorates one's quality of life". To see if the objection stands on a valid ground requires us a simple task: check if the facts provided are indeed factual.

A review of scientific studies concerning living kidney donation in the past forty years reveal that these alleged facts are without any empirical basis. For one, scientific studies show that kidney donation does not shorten life. There is no known and recognized risk that shortens life expectancy in kidney donation. As Jeffrey P. Kahan, Ph.D., M.P.H., Director of the Centre for Bioethics at the University of Minnesota, points out: "There is little, if any, increased risk associated with living with only one kidney"7.

Indeed, published reports show similar life expectancy of donors to people the same age that did not donate a kidney. One of such well-known published studies is performed by Fehrman-Ekhol, I. (1997), while other studies (e.g. Undurraga, A. et al., 1998; Najarian, et al., 1992, etc.) strongly suggest that there are few, if any, long term consequences from donating a kidney ${ }^{8}$.

On the assertion that it undermines quality of life, there are, again scientific studies to confirm the contrary.

Reports show that kidney donors can normally pursue their "lifting of heavy objects" within six weeks-and beyond the normal period of recuperation (after two to three months), donors can normally pursue their self-defined projects (pursuing life activities normally e.g. playing one’s favorite sports, etc.).

The kidney recipient who lost his two natural kidneys, and only has one "transplanted" kidney should be worse-off-and yet it is too common to hear stories of recipients who are back in their normal life enjoying what they have been enjoying before their kidney transplantation: skating, playing back in the hard court, etc ${ }^{10}$.

\footnotetext{
${ }^{6}$ Refined surgical techniques and post-donation medical care have greatly reduced the risk of kidney donation—as the study conducted by the American Society of Transplant Surgeons, among many other similar studies, shows, the mortality risk is $0.03 \%$ (i.e. three deaths for every 10,000 procedures). There is a greater risk of dying in an automobile accident than in kidney donation. Other scientific and verifiable data to support the argument that certain forms of organ donation (kidney donation and other non-lethal donations) are acceptable in Kantian ethics are presented in addressing the second Kantian condition.

${ }^{7}$ Kahn, J. P. (1998) Would You Give a Stranger Your Kidney? The Ethics of "Unknown” Kidney Donors. "Ethics Matters” Center for Bioethics and CNN Interactive. http://www.cnn.com/HEALTH/bioethics/9807/stranger.kidney/ [last accessed July 8, 2014: 4:00 pm].

${ }^{8}$ This Swedish study evaluated the life span of living kidney donors. Of 430 people who donated between 1964 and 1994, 41 died from 18 months to 31 years following donation - the causes of death include cardiovascular disease, cancer, injury or accidents, gastrointestinal disease, alcoholism, and other diseases. None died of kidney disease. The study also concluded that the survival rates of donors were higher than the general population, possibly due to the careful selection of donors based on their health (i.e., donors tend to be healthier than the general population). For a digest of other relevant published reports see: Staying Healthy after Donation. Living Donors Online! http://www.livingdonorsonline.org/kidney/kidney6.htm

${ }^{9}$ ASTS study on living kidney donation (1992). http://www.asts.com/reports/kidney/ [last accessed July 8, 2014: 4:00 pm].

${ }^{10}$ To cite few examples, we have the National Basketball star Shawn Sean Elliot, American baseball star Mickey Mantel, former Pennsylvania governor Robert Casey, actor Larry Hagman, and rock star David Crosby. See Joralemon, D. (2001) Shifting ethics: Debating the incentive question in organ transplantation. J. Med. Ethics 2001; 27:30-35 doi:10.1136/jme.27.1.30.
} 
How could be the donor, who gives one of his kidney while retaining one, which is naturally his, is worst-off than the recipient?

Of course there are reports that some "organ donors" suffer deteriorating quality of life but the cause of the deterioration is not attributable to donation itself. Organ donors who usually complain about the deterioration of their quality of life are mostly those who have "sold" their organs, (hence, left without, or with inadequate, postdonation medical care), and people who fail to observe proper care after the procedure (people who forgo routine medical checkups, failure to take proper medication, etc.).

All these point to one thing: that the objection against living organ donation (i.e. kidney donation and other forms of non-lethal transplantation) that it both shortens life and deteriorates quality of life is unfounded.

Now, if it does not undermine the personality of the donor (as end-setting agents), neither it deteriorates his quality of life (the donor is not worst-off for donating his kidney), in light of the second condition of mutilation, we can see that organ donation is not contrary to duty of self-preservation.

We now come to the third condition of Kantian concept of mutilation: Amputation of organs constitutes a crime against one's own person when the primary reason is the sale of organs or when "amputation" of organs is considered as means of livelihood.

As we can see, this does not pose any serious problem to organ donation (as a surgical procedure)—but rather, it generally concerns the intention of the donor in "donating" his organs. In other words, it has something to do with organ procurement or how organs ought to be acquired from donors-either donation strictly based on beneficence (or altruism) or donation with compensation (or financial incentives). In either cases, it is pointed out that Kant does not allow selling of bodily parts (recall the tooth, the hair and the testicle examples).

If, for instance, the organ donor "gives up" his kidney in exchange for a sum of money, then kidney "donation" in this case would be unacceptable for Kant. Here, the primary motive of the donor is to sell. The body is treated as a mere means, a thing, which is arbitrarily used. However, if assuming that the organ donor has for himself another motive than selling (e.g. motive of duty to help) as his primary reason for donating his organ (which we could possibly know through the donor's maxim)—will organ donation, in light of this third Kantian condition, be considered as mutilation, hence, violative to his duty of self-preservation? The answer is obvious: no it does not.

If the primary motive is not selling of organs, then organ donation is not violative of the Kantian concept of mutilation.

\section{Conclusions}

It is more Kantian to claim that Kant does not categorically prohibit all forms of organ donation. As previously shown in the preceeding sections, there are certain forms of organ donation that do not qualify to the Kantian conception of mutilation.

It could be argued, that in cases where the donation is primarily motivated not by mere inclination (i.e. desire to help a love one, or a friend in need, etc.) but rather, by motive of duty (i.e. because it is one's duty to help people in dire need and the donor is in the position to help), the act of donating an organ can be considered, not only as permissible, but morally commendable.

The statement that kidney and bone marrow donations, and to the degree that partial grafts of liver and lung tissue, which do not involve transplantation of the entire organ, are becoming safe and successful for both donor and recipient, are great acts of love and kindness, and find new meaning in light of the new Kantian paradigm which this paper has painfully shown.

\section{Acknowledgements}

My heartfelt thanks to Dr. Romeo R. Quilang, University President, Cagayan State University and to Dr. Jose P. Guzman, Vice-President for Research and Extension, Cagayan State University, for their selfless support.

\section{References}

ASTS Study on Living Kidney Donation (1992). http://www.asts.com/reports/kidney/

Herman, B. (2001). The Practice of Moral Judgment. Cambridge, MA: Harvard University Press.

Joralemon, D. (2001) Shifting Ethics: Debating the Incentive Question in Organ Transplantation. Journal of Medicine and 
Philosophy, 27, 30-35. http://dx.doi.org/10.1136/jme.27.1.30

Kahn, J. P. (1998). Would You Give a Stranger Your Kidney? The Ethics of “Unknown” Kidney Donors. “Ethics Matters” Center for Bioethics and CNN Interactive. http://www.cnn.com/HEALTH/bioethics/9807/stranger.kidney/

Kant, E. Groundworks for Metaphysics of Morals. Translated and Edited by James Ellington, (1981). Cambridge: Hackett Pub. Co., Inc. $3^{\text {rd }}$ Edition.

Kant, E. Metaphysics of Morals. Translated and Edited by May Gregor (1996). Cambridge: Cambridge University Press.

Land, W. (1999). Ethics in Living Donor Organ Transplantation. Transplantation Center of the University of Munich. Langenkefks Archives of Surgery. October 1999.

Staying Healthy After Donation. Living Donors Online! http://www.livingdonorsonline.org/kidney/kidney6.htm 
Scientific Research Publishing (SCIRP) is one of the largest Open Access journal publishers. It is currently publishing more than 200 open access, online, peer-reviewed journals covering a wide range of academic disciplines. SCIRP serves the worldwide academic communities and contributes to the progress and application of science with its publication.

Other selected journals from SCIRP are listed as below. Submit your manuscript to us via either submit@scirp.org or Online Submission Portal.
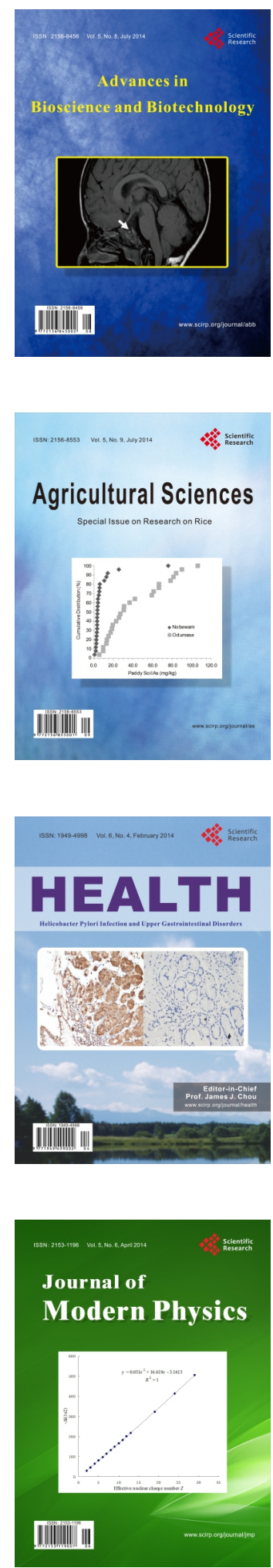
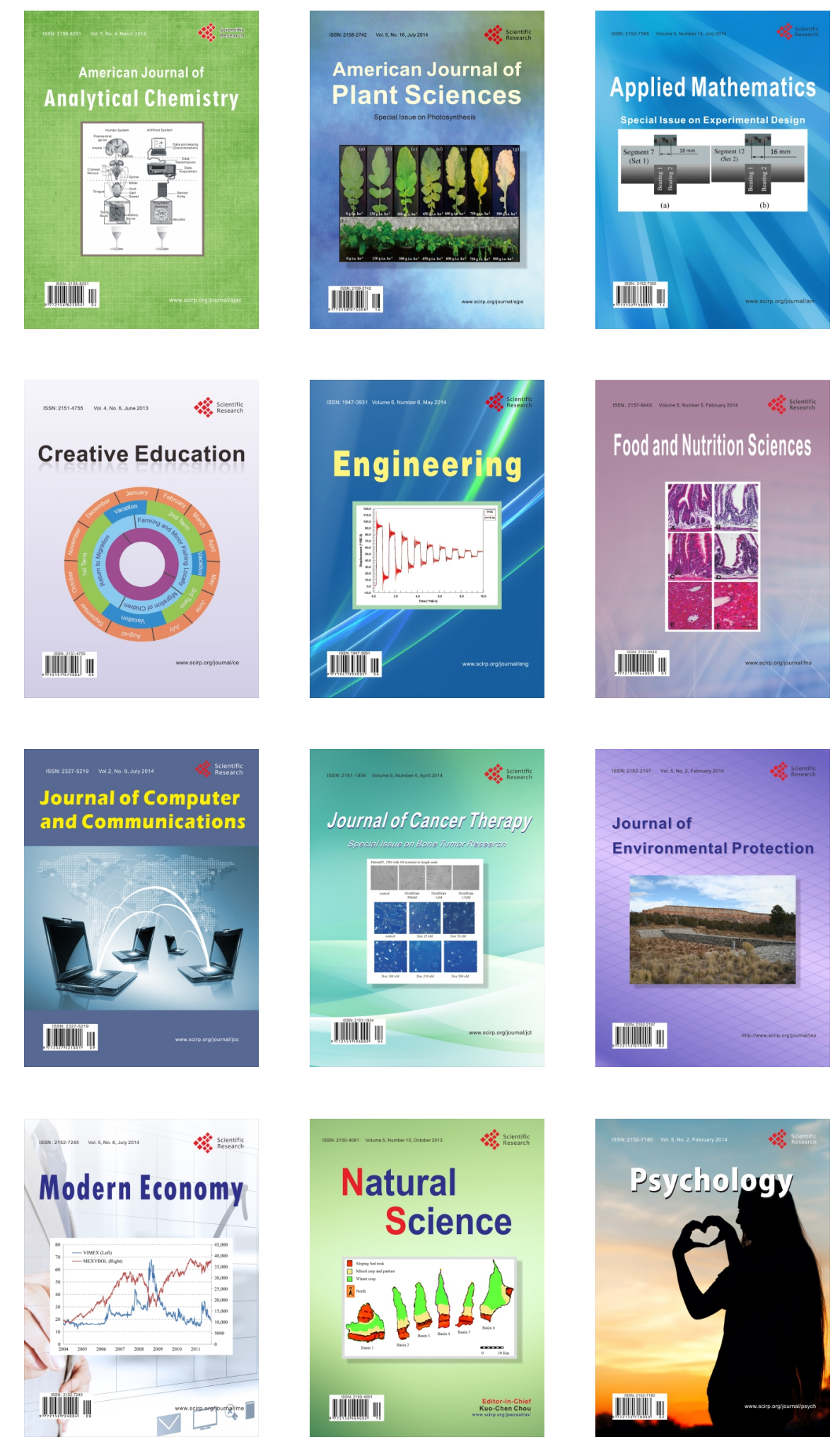